\title{
Animal Welfare in Terms of Assessing Sheltering Conditions in Farms Studied. Part II
}

\author{
Cristina EL MAHDY*1), Silvana POPESCU ${ }^{2)}$, Cristin BORDA ${ }^{2)}$, Anca BOARU ${ }^{1)}$ \\ 1)Faculty of Animal Science and Biotechnologies, University of Agricultural Sciences and Veterinary \\ Medicine, 3-5 Mănăştur Street, 400372 Cluj-Napoca, Romania \\ ${ }^{2}$ )Faculty of Veterinary Medicine, University of Agricultural Sciences and Veterinary Medicine, 3-5 \\ Mănăştur Street, 400372 Cluj-Napoca, Romania \\ *Corresponding author, email: cristina.hegedus@yahoo.com
}

Bulletin UASVM Animal Science and Biotechnologies 71(2) / 2014,

Print ISSN 1843-5262; Electronic ISSN 1843-536X

DOI:10.15835/buasvmcn-asb:10464

\begin{abstract}
The values obtained in each section and afferent criteria indicate a total score of 20.5 points (F1), 15.0 points (F2), 19.0 points (F3), 18 points (F4), 20.5 points (F5). Lowest score obtained in all farms resulting from the assessment of the system maintenance: tie-stall in winter, resting surface (locomotion), social interaction. Here an essential role it played animals able to move in the summer grazing, which leads to increased scores on this indicator.

Air quality and lighting conditions during the winter season presents deficiencies resulting from reduced norm natural and artificial lighting and air volume of shelters that indicate high values of chemical parameters $\mathrm{CO}_{2}$ and $\mathrm{NH}_{3}$ during winter and ventilation through the opening windows produce air currents with high speed movement. Partial scores for this segment have values between 2 (F3, F1) and 1 (F2, F4) out of the 9.5 points as possible. Animal suffer in the winter because of deficiency related with the technical condition of water system and degree of cleanliness of this area, where the points awarded was -0.5 /each farms. By this cause for stockmanship criteria the score are very low.
\end{abstract}

Keywords: ANI 35L/2000, dairy cow, welfare

Introduction. To complete the overall image of the dairy farms studied was assessed the essential requirements of animals, taking into account aspects related with: locomotion, social interaction, flooring, light and air, stockmanship and assessing sheltering conditions after system proposed by Bartussek et al. (2000), 35 ANI L/2000 being a method with multiple repeatability. ANI35L/2000 is a tool to identify sheltering deficiencies and weaknesses, which create discomfort to the cows, and the possibility of remediation. Caring for animals take into account the all aspects of environmental and the dependent on the animal mean welfare (Alger Boss et al., 2009). Not just feeding, watering the animals go to maintain of animal health and production but also high level of comfort and air quality in that the animals live (Drăghici, 2001). Importance of resting space reflects on comfort, feeding, rumination, milk quality (Grant et al., 2009).

Materials and methods. After the study that was made in first part and the results being discussed on "Aspects of the welfare of dairy cows in farms with tied- stall maintenance system and action of the upstream factors. Part I" could do made the characterization of the welfare condition in all the five farmers after ANI $35 \mathrm{~L} / 2000$ cattle (Animal Needs Index for Cattle) which consist in 5 main criteria, each criteria having subcriteria who were noted. Cumulating all the scores, finally we were able to identified the degree of welfare in each farms.

Assessment of indicators was performed by the methods described in fist part of work paper, carried out inside of shelters but also from direct observations on animals. 
Results and discussion. The total score for locomotion criteria were 4 for F1, F2, F3, F4 and 3 for F4. A score much lower, 3 (F1, F2, F3, F4, F5) was awarded for social interaction criteria of 10 points maximum. This score depends by maintenance system, tethered during winter without outside access and the size of stand: 1.6 $\mathrm{mp} /$ head F2, $2.05 \mathrm{mp} / \mathrm{F} 1$ (short sand), $2.24 \mathrm{mp} /$ head F3, $2.47 \mathrm{mp} / \mathrm{F} 4,2.26 \mathrm{mp} /$ head F5 (medium stand). The total score awarded for flooring area (minimum 2.5 points, maximum 8 points) are: 7 points (F1, F4), 6.5 points (F3). Minimum score 4.5 points received F2 farms and maximum: 7.5 (F5).

For the environmental condition inside of the shelter related with light and air criteria (minimum 2 , maximum 9.5 points) in 3 for all five farms, the daylight was noted with 0.5 because of lighting index calculated: 1/30 (F2) - 1/32 (F3) and with 1 for $F 1\left(L_{i}=1 / 20\right), F 2\left(L_{i}=1 / 22\right)$. For air quality, the volume of air is insufficient/head. The cumulated $\mathrm{CO}_{2}$ show deficiency compared with ANI 35 $\mathrm{L} / 2000$ cattle. $\mathrm{NH}_{3}$ even if is under limit after a lot of author, the concentration is constantly and much higher related with the value of this index. So this parameter was noted with -0.5 in all five farms. Overall score shows big deficiencies related with this criteria: 2 points (F1, F2), 1.5 points (F2, F4), 1.5 points (F5).

The lower score for stockmanship criteria was given for cleanliness of feeding/drinking area and technical condition of equipment. It was find residuum of feed in drinking systems in most all the time. The most problems in winter season by point of view of technical condition is related by drinking system and dairy cow possibility to have access at water. Each farmers has own source of water and because pipelines are not buried and installation freezes. For this reason the score giving for this two sub criteria is -0.5 . Per overall, the score for this criterion is by: 4.5 (F1), 3.5 (F2), 3.5 (F3), 3 (F4), 4.5 (F5).

The total score/farms reveal deficiencies from the needs regarding the animals. The biggest score was obtained in F1 and F5 farms (20.5 point /each farms) and the lowest score belongs to the farm F2 (15 point). The F3 farm (19 point) and F4 (18 point) show quite similar conditions.

Conclusion. Critical points are found in each of the sections evaluated less grazing which otherwise a raised the score in each farm. Following the assessment and scoring obtained welfare of dairy cows is poor.

\section{REFERENCES}

1. Algers Bosse (2009). Effects of farming systems on dairy cow welfare and disease Annex to the EFSA Journal (2009) 1143: 1-242.

2. Bartussek H, Ch Leeb, S Held (2000). Animal Needs Index for Cattle. ANI 35L/2000-cattle. Federal Research Institute for Agriculture in Alpine Region BAL Gumpenstein, A 8952Irdning, of the Federal Ministry Of Agriculture and Forestry, Environment and Watermanagement, Austria.

3. Drăghici C (2001). The animal hygiene and environmental protection.Ed Risoprint, Cluj-Napoca.

4. Grant R (2013). Effects of Cow Comfort on Milk Quality, Productivity, and Behavior. http://www.extension.org 